\title{
A simple alternative to line transects of nests for estimating orangutan densities
}

\author{
van Schaik, Carel P ; Wich, Serge A ; Utami, Sri Suci ; Odom, Kisar
}

\begin{abstract}
We conducted a validation of the line transect technique to estimate densities of orangutan (Pongo pygmaeus) nests in a Bornean swamp forest, and compared these results with density estimates based on nest counts in plots and on female home ranges. First, we examined the accuracy of the line transect method. We found that the densities based on a pass in both directions of two experienced pairs of observers was $27 \%$ below a combined sample based on transect walks by eight pairs of observers, suggesting that regular line-transect densities may seriously underestimate true densities. Second, we compared these results with those obtained by nest counts in 0.2 -ha plots. This method produced an estimated 15.24nests/ha, as compared to 10.0 and 10.9, respectively, by two experienced pairs of observers who walked a line transect in both directions. Third, we estimated orangutan densities based on female home range size and overlap and the proportion of females in the population, which produced a density of 4.25-4.5 individuals/ $\mathrm{km} 2$. Converting nest densities into orangutan densities, using locally estimated parameters for nest production rate and proportion of nest builders in the population, we found that density estimates based on the line transect results of the most experienced pairs on a double pass were 2.82 and 3.08 orangutans $/ \mathrm{km} 2$, based on the combined line transect data are 4.04 , and based on plot counts are 4.30. In this swamp forest, plot counts therefore give more accurate estimates than do line transects. We recommend that this new method be evaluated in other forest types as well
\end{abstract}

DOI: https://doi.org/10.1007/s10329-005-0134-z

Posted at the Zurich Open Repository and Archive, University of Zurich

ZORA URL: https://doi.org/10.5167/uzh-155867

Journal Article

Published Version

Originally published at:

van Schaik, Carel P; Wich, Serge A; Utami, Sri Suci; Odom, Kisar (2005). A simple alternative to line transects of nests for estimating orangutan densities. Primates, 46(4):249-254.

DOI: https://doi.org/10.1007/s10329-005-0134-z 


\section{A simple alternative to line transects of nests for estimating orangutan densities}

Received: 29 September 2003/ Accepted: 29 March 2005/Published online: 28 June 2005

(C) Japan Monkey Centre and Springer-Verlag 2005

\begin{abstract}
We conducted a validation of the line transect technique to estimate densities of orangutan (Pongo pygmaeus) nests in a Bornean swamp forest, and compared these results with density estimates based on nest counts in plots and on female home ranges. First, we examined the accuracy of the line transect method. We found that the densities based on a pass in both directions of two experienced pairs of observers was $27 \%$ below a combined sample based on transect walks by eight pairs of observers, suggesting that regular linetransect densities may seriously underestimate true densities. Second, we compared these results with those obtained by nest counts in 0.2-ha plots. This method produced an estimated 15.24 nests/ha, as compared to 10.0 and 10.9, respectively, by two experienced pairs of observers who walked a line transect in both directions. Third, we estimated orangutan densities based on female home range size and overlap and the proportion of females in the population, which produced a density of 4.25-4.5 individuals $/ \mathrm{km}^{2}$. Converting nest densities into orangutan densities, using locally estimated parameters for nest production rate and proportion of nest builders in the population, we found that density estimates based on the line transect results of the most experienced pairs on a double pass were 2.82 and 3.08 orangutans $/ \mathrm{km}^{2}$, based on the combined line transect data are 4.04 , and
\end{abstract}

C. P. van Schaik $(\bowtie)$

Anthropologisches Institut und Museum, Universität Zürich, Winterthurerstrasse 190, 8057 Zürich, Switzerland

E-mail: vschaik@aim.unizh.ch

Tel.: + 41-1-6355410

Fax: + 41-1-6356804

S. A. Wich

Department of Behavioural Biology, Utrecht University, PO Box 80086, 3508TB Utrecht, The Netherlands

S. S. Utami

Fakultas Biologi, Universitas Nasional, J1 Sawo Manila, Pejaten, Pasar Minggu, Jakarta, Indonesia

K. Odom

Kantor Mawas, Jl Yos Sudarso 1A, Palangkaraya,

73112, Kalimantan Tengah, Indonesia based on plot counts are 4.30. In this swamp forest, plot counts therefore give more accurate estimates than do line transects. We recommend that this new method be evaluated in other forest types as well.

Keywords Census $\cdot$ Methods $\cdot$ Plot counts $\cdot$ Pongo

\section{Introduction}

Effective conservation of a species necessitates basic information about densities, population sizes, and trends. Relative densities, or indices, can be used to indicate trends in numbers and compare areas with respect to conservation priority, but absolute estimates of numbers, and hence densities, are required for estimates of population size and vulnerability to extinction (Cowlishaw and Dunbar 2000). Obtaining estimates of absolute numbers can, however, be very difficult. Orangutans (Pongo spp.), for example, are semi-solitary, non-territorial, arboreal and cryptic forest animals that often live at low densities. It is therefore difficult to count them directly and, if animals hide from observers, as in areas where they are hunted, line transects will systematically underestimate densities. However, great apes regularly build sleeping platforms, or nests, that can be counted with greater ease. Some two decades ago, chimpanzee researchers began using estimates of nest densities obtained through line transects, which can be converted into animal densities when the values of various parameters are known (Ghiglieri 1984; Hashimoto 1995). Since its application to orangutans in the early 1990s (van Schaik et al. 1995), this technique has been improved incrementally (Buij et al. 2003; Johnson et al. 2005 ), and is now widely used to produce estimates of orangutan densities (Russon et al. 2001; Buij et al. 2002; Morrogh-Bernard et al. 2003; Ancrenaz et al. 2005). In this paper, we first briefly review the technique then describe an experiment to test its adequacy, and finally present the results of a simple alternative plot-count 
method that is more accurate, as assessed by comparison with a direct estimate of density.

The line transect technique for orangutan nests and its problems

The general equation for estimating the densities of nests is:

$d=\frac{N}{L \times w \times 2}$,

where $d$ is the density of nests in numbers $/ \mathrm{km}^{2}, N$ the number of nests observed along the transect, $L$ the length of the transect line in $\mathrm{km}$, and $w$ the estimated strip width in $\mathrm{km}$. This nest density can be converted into orangutan density in number $/ \mathrm{km}^{2}$ (Ghiglieri 1984; van Schaik et al. 1995), using:

$D=\frac{d}{p \times r \times t}$,

where $p$ is the proportion of the population making nests, $r$ the rate of nest production (number of nests per capita per day), and $t$ is the time to disappearance of the average nest in days. The line transect technique must overcome (1) the problems of estimating the additional parameters, and (2) the difficulties inherent in the use of line transects.

The problem with the additional parameters is that they need to be estimated, and are only known with some error, compounding the error in the eventual orangutan density estimate. The parameters $p$ and $r$ must be estimated from long-term field studies of habituated animals. The results show that $p$ is fairly constant across sites, but that $r$ can vary appreciably, with Sumatran populations (van Schaik et al. 1995; Singleton 2000) building nests at far higher rates than Bornean ones (Gunung Palung: Johnson et al. 2005; Kinabatangan: Ancrenaz et al. 2005; Tuanan: see Results). It turns out that it is most difficult to estimate $t$, which appears to be quite variable, but without straightforward environmental correlates (Buij et al. 2003; Johnson et al. 2005). In long-term studies, direct monitoring of the survival of nests made at known dates produces reliable estimates. Where repeat surveys are available, $t$ can also be estimated by recording the transitions between decay stages of the nests and by considering the decay process a Markov chain with an absorbing end state (van Schaik et al. 1995), which has been shown to produce good estimates (Buij et al. 2003; Johnson et al. 2005). Thus, while the additional parameters needed to convert nest density into orangutan density cannot be estimated without error, these estimates have become fairly accurate.

The second difficulty stems from the line transect technique itself. Among the basic assumptions of this technique (Buckland et al. 1993), the most problematic one is that all objects on the line (in forests: above the line) are encountered. Although it is not known what proportion of nests directly above or near the transect line are missed, there will always be some that escape detection. The existence of this problem, illustrated in Fig. 1, is demonstrated by two observations. First, more experienced observers generally produce higher density estimates than less experienced observers, while, if this assumption is met, they should merely detect objects in a broader strip and thus produce similar densities, albeit with narrower confidence limits. Second, repeat surveys of the same line in the opposite direction generally not only add nests, but actually yield higher density estimates when the samples are pooled (van Schaik et al. 1995; Buij et al. 2003; Johnson et al. 2005).

Workers have therefore attempted to produce a correction for this deficit. First, the repeat survey can be used to produce a corrected estimate (Johnson et al. 2005). However, although the new estimate is closer to the true density, it remains unknown how close (see Fig. 1b). Second, one can develop an empirical correction factor by comparing calculated densities with known densities (Buij et al. 2003). However, this procedure also appears to be unsatisfactory because there is no general prediction as to the size of this factor, nor its relationship with forest structure or other obvious ecological factors. In conclusion, even if all parameters have been estimated correctly, the method will generally still produce an underestimate of the true density by an unknown margin.

In this paper, we make two independent attempts to develop more accurate density estimates. First, we examine the results of an experiment in which the results of two experienced pairs of observers who surveyed the same transect lines in both directions were compared to the combined sample of these two and an additional six pairs. Second, we examined a simple alternative method, based on complete counts of small plots. The results of
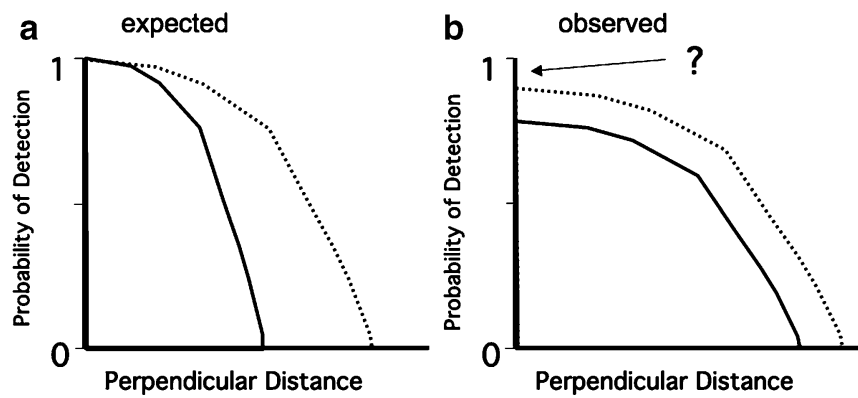

Fig. 1 The effect of observer experience on estimated densities of objects surveyed through line transects. In (a) experienced (dotted line) and naïve observers (solid line) behave as expected by the method, i.e. both observe all objects on the line, but differ in how well they observe objects away from the line. In practice, their difference resembles that in (b), where experienced observers observe more objects, both on the transect line and away from it. It is unknown, however, whether even experienced observers detect all objects on the line. The effect of including a second pass of the trail in opposite direction can also be represented in this way: new nests are detected mainly away from the line (a) or everywhere (b) 
these two attempts are compared with an estimate based on direct observations of orangutans, in particular the size and overlap of female home ranges.

\section{Methods}

The study was conducted in August 2003 at the Tuanan study area in the Mawas Reserve, Central Kalimantan, Indonesia. This site $\left(2^{\circ} 09^{\prime} 06.1^{\prime} \mathrm{S}, 114^{\circ} 26^{\prime} 26.3^{\prime} \mathrm{E}\right)$ consists of peat swamp on shallow peat, of varying thickness, up to about $2 \mathrm{~m}$. It is disturbed, having been subject to selective commercial logging in the early 1990s, followed by almost a decade of informal logging by local people. Line-transect surveys of nests of Bornean orangutans (Pongo pygmaeus wurmbii) were conducted along a recently established $2.5-\mathrm{km}$-long narrow boardwalk, which follows trails that had been cut in a regular grid.

In a 2-day period, eight different pairs of observers walked the same transect $(1.25 \mathrm{~km} /$ day $)$. On a given day, a pair walked the transect line in both directions (henceforth referred to as the first and second pass, respectively). To facilitate comparisons among teams, for each nest encountered, each team recorded location (trail coordinate), perpendicular distance to the boardwalk, decay class, and height in 5-m classes. Perpendicular distances were measured to the nearest $0.5 \mathrm{~m}$. Location was estimated by reference to $50-\mathrm{m}$ trail markers, using the length of boards $(4 \mathrm{~m}$ each) for additional reference.

The teams varied in experience: two of them were composed of people who had much experience (teams 1, 2 ) in nest surveys, whereas the other six teams (students and staff of Universitas Nasional, Jakarta) had no experience, although several had followed orangutans and all were at least familiar with orangutan nests.

At the completion of the eight team nest surveys, the two most experienced teams rechecked all nests to produce a combined sample in which all nests recorded by at least one team were included. This step was necessary to avoid the double counting of nests that differed slightly in recorded location, perpendicular distance, or height class, and to ensure use of the same definition of nests among observers (which is especially important for the final stages of decay, as defined in van Schaik et al. 1995).

Strip width $(w)$ was estimated using DISTANCE 4.0 (Thomas et al. 2001). Perpendicular distances were truncated at $30 \mathrm{~m}$ (six cases, or approximately 5\%). We followed the same procedure as Buij et al. (2003), based on the five models recommended by Buckland et al. (1993), to which the observed distribution of perpendicular distances were fitted. Calculations were made for each team, one for the first pass and one for the first and second pass combined. Only a single calculation could be done for the combined sample, representing both passes. A 95\% confidence limits were calculated for the estimated strip width based on the analytical variance option in DISTANCE, and were used to estimate the confidence limits in orangutan density (i.e. assuming no error in the other parameters).

We established 11 plots of 0.2 ha each, by taking a $50-\mathrm{m}$ stretch of the transect line and adding a $20-\mathrm{m}$ strip perpendicular to the line on either side. Plots along the same transect line were $200 \mathrm{~m}$ apart in order to avoid sampling the same clusters of nests if nests tend to be distributed in a clumped way around major food trees and, thus, ensures independence of plot counts and similar habitat coverage as the line transects. An additional ten similarly spaced plots were established along two trails elsewhere in the study area. In each plot, a team of three experienced observers attempted to locate all nests. They were allowed to move both inside and outside the plot and for as long as they deemed necessary. The location of each nest was carefully measured to establish whether it was located within the plot.

Estimated densities using these indirect methods were also compared with our best estimate of the true density based on long-term follows of identified orangutans. Adult female density was estimated as the number of home ranges among six identified individuals stacked at a single point divided by mean female home range size; this density was subsequently extrapolated to the whole population based on estimated population composition (cf. Singleton and van Schaik 2002). We superimposed a grid on the 200-ha portion of the study area that was most intensively sampled. In this grid, we counted for each of 42 regularly spaced points the number of home range of adult females known to include this point. Mean home range size for four intensively studied adult females (>750 h each) was 245 ha (Wich and van Schaik, unpublished). Extrapolation to the whole population was done using the following estimated composition: 0.9 infants; 0.4 juveniles and adolescents; $0.8-1$ unflanged and flanged sexually mature males (the first two of these numbers are based on direct observations, the latter is an estimate based on male-biased sex ratios at birth combined with male-biased adult mortality; cf. Singleton and van Schaik 2002). Hence, 3.1-3.3x adult female density is an estimate of overall orangutan density.

\section{Results}

Line transect counts

The main results are summarized in Table 1. Experienced teams detected significantly more nests after the first pass $(76,87)$ and after both passes $(85,98)$ along the 2.5-km line transect than any of the six inexperienced teams (means: 42.5 and 49 nests, respectively; MannWhitney $U$-tests: $U=0, P<0.05$, in both cases). They did not differ much from the inexperienced teams in the percentage of nests added due to the second pass in the opposite direction (12 and 13\% for the two experienced teams vs mean of $15.7 \%$ for the six inexperienced teams). Experienced teams tended to produce the highest 
Table 1 Overview of the line transect results of counts of orangutan (Pongo spp.) nests for the experienced teams $(1,2)$, the other six teams (3-8), and the combined sample including all teams, for both the first pass (First) and the pooled sample of the passes in both directions of the transect line (First + second)

\begin{tabular}{|c|c|c|c|c|c|c|c|c|c|c|}
\hline \multirow[t]{2}{*}{ Team } & \multicolumn{2}{|c|}{$N$ nests } & \multicolumn{4}{|c|}{$w$ Estimate $(\mathrm{m})$ and criterion selected } & \multicolumn{2}{|c|}{ Nest density/ha } & \multicolumn{2}{|c|}{$\begin{array}{l}\text { OU density } \\
\left(d / \mathrm{km}^{2}\right)^{\mathrm{a}}\end{array}$} \\
\hline & First & $\begin{array}{l}\text { First }+ \\
\text { second }\end{array}$ & First & Criterion & Second & Criterion & First & $\begin{array}{l}\text { First }+ \\
\text { second }\end{array}$ & $t=300$ & $t=350$ \\
\hline Exp-1 & 76 & 85 & 14.55 & Half-normal & 15.59 & Half-normal & 10.45 & 10.90 & 3.59 & 3.08 \\
\hline Exp-2 & 87 & 98 & 19.04 & Hazard rate & 19.59 & Hazard rate & 9.14 & 10.01 & 3.29 & 2.82 \\
\hline Inexp-3 & 49 & 59 & 12.64 & Uniform-cosine & 13.61 & Uniform-cosine & 7.75 & 8.67 & 2.86 & 2.45 \\
\hline Inexp-4 & 29 & 35 & 18 & Uniform-key & 20 & Uniform-key & 3.22 & 3.5 & 1.16 & 0.99 \\
\hline Inexp-5 & 52 & 62 & 11.95 & Uniform-cosine & 11.88 & Uniform-cosine & 8.70 & 10.44 & 3.44 & 2.95 \\
\hline Inexp-6 & 35 & 43 & 14.27 & Half-normal & 13.25 & Uniform-cosine & 4.91 & 6.49 & 2.14 & 1.83 \\
\hline Inexp-7 & 47 & 51 & 13.08 & Uniform-cosine & 12.81 & Uniform-cosine & 7.19 & 7.96 & 2.63 & 2.25 \\
\hline Inexp-8 & 43 & 44 & 12.27 & Uniform-cosine & 12.19 & Uniform-cosine & 7.01 & 7.22 & 2.38 & 2.04 \\
\hline Combined & - & 129 & - & - & 18.01 & Uniform-cosine & - & 14.33 & 4.71 & 4.04 \\
\hline
\end{tabular}

${ }^{\mathrm{a}}$ Reporting only density estimates for first and second pass combined, using $p=0.88$ and $r=1.15$

nest densities, at 10.0 and 10.9 nests/ha, but one of the inexperienced teams also reached a similar density (10.4) (Mann-Whitney $U$-test, $U=1 ; 0.05<P<0.10$ ). The increase in nest density due to the second pass was marginally lower for the experienced pairs $(4.4$ and $9.5 \%)$ than for the other teams (mean: 14.4). Overall, then, experienced observers detect more nests and tend to produce higher density estimates.

The number of confirmed nests seen by at least one team, which provides the best estimate of the number of nests that could be seen by human observers walking the transect line, was 129. This number corresponds to 14.33 nests/ha, using the $w$ estimate for all these nests ( $w$ $=18.01$, choosing the perpendicular distance randomly from among the teams that had recorded the nest). The comparison indicates that the experienced teams still missed a considerable number of nests that could potentially be seen. Thus, they achieved only 73 and $64 \%$ of the best estimate after the first pass, and 76 and $70 \%$, respectively, of this best estimate after passing the transect line in both directions. This finding suggests that single-pass line transect estimates of even experienced nest counters can underestimate the best possible density based on line-transects by at least $30 \%$, whereas double-pass estimates still underestimate it by an average of at least $27 \%$.

Plot counts

The 11 plots along the transect lines yielded a mean number of 3.09 nests (SD 1.87), corresponding to a nest density of 15.5 nests/ha. The estimated nest density based on the combined sample for the same part of the transect line as covered by the plots was 15.0 (based on 27 nests, and using the $w$ estimate for the whole sample of 129 nests). The value of 15.0 nests/ha, however, is still $44 \%$ higher than the mean value of the two experienced line-transect teams (who had 10.0 and 10.9 nests/ha).
An attempt was made for the plot counts to be complete. Plot counts were more complete than the line transect counts of the same transect segments. Given a $w$ value of $18.0 \mathrm{~m}$ in the combined sample, the expected number of nests in the plot based on the transect count would have been $27 \times(20 / 18)=30$. Thus, with 34 observed nests, plots provide a $13 \%$ better coverage than transect lines, although plots were still not perfect: three nests that had been recorded along the transect line were subsequently missed during the plot counts. Correcting again for the $w$ value of $18.0 \mathrm{~m}$ in the combined sample, this would translate to a number of missed nests of $3 \times(20 / 18)$, or 3.33 nests of a total of 34 recorded nests. Hence, the overall best estimate of the true density of nests would be 37.33 nests in 2.2 ha, or 16.97 nests/ha.

Because the number of independent and hence, widely spaced plots along the line transect was limited, we also placed an additional ten plots elsewhere in the study area in similar habitat. Their mean number of 3.00 nests per plot hardly changes the mean estimated nest density: 15.24 nests/ha. Thus, even the small sample of plots considered here can be considered adequate to characterize the nest density. The mean and $95 \%$ confidence limits for the density based on 11 plots are therefore $15.45 \pm 6.28$, and for the one based on all 21 plots are $15.24 \pm 5.31$. Obviously, inclusion of more plots narrows the confidence limits.

\section{True density and comparison}

The average point in the grid is included in 3.36 home ranges of known adult females. Female density is therefore 1.37 adult females $/ \mathrm{km}^{2}$, and total orangutan density at Tuanan is therefore $4.25-4.5$ individuals $/ \mathrm{km}^{2}$. Thus, densities based on indirect methods can be compared to this best estimate of the true density.

Comparisons with the nest-based estimates are made possible by extensive direct observations at Tuanan, which produced local estimates of $p$, and $r$. Because 34 
of 37 focal animals built nests, we estimate $p=0.88$. Based on a sample of 391 complete focal follow days, and using an average of the means per age-sex class weighted for representation in the population, we estimate $r=1.15$. To estimate $t$, we follow Morrogh-Bernard et al.'s (2003) most conservative estimate for Sebangau, the nearest site with similar habitat, at 350 days.

In Table 2, we summarize the results of the various techniques. Whereas the line transect technique underestimates densities (although the cumbersome combined sample including all observers does so to the smallest extent), the plot counts provide estimates close to the estimated true density of 4.5 individuals $/ \mathrm{km}^{2}$. Confidence limits are relatively higher for the plots than for the line transects based on individual pairs, as expected because of the larger number of nests sampled in the line transects. Thus, a relatively larger number of plots would be needed to reach similar reliability as in line transects, but a small number of plots already gives a more accurate estimate.

\section{Discussion}

The simple experiment in nest surveying produced three interesting findings about line transects of nests. First, experience matters: inexperienced teams generally produced lower estimates than experienced teams, contrary to the naïve expectation that lack of experience will be compensated for by narrower strip widths. Second, line transects underestimate nest densities: even highly experienced teams tended to underestimate nest density by an average of $27 \%$. This estimate is conservative because even the combined sample missed some nests right above or near the trail. Third, the second pass, while increasing the estimated nest density, still yielded density estimates well below the realistic minimum estimate. R. Buij (personal communication) and Johnson et al. (2002) also noted an increase in the number of nests on the second pass. Their increases were higher, 20

Table 2 Summary comparison of the results of different methods of estimating orangutan densities in Tuanan (assuming $p=0.88$, $r=1.15$, and $t=350$ )

\begin{tabular}{|c|c|c|}
\hline Method & $\begin{array}{l}\text { Density } \\
\left(d / \mathrm{km}^{2}\right)\end{array}$ & $\begin{array}{l}95 \% \text { confidence } \\
\text { limits }\end{array}$ \\
\hline $\begin{array}{l}\text { Line transect: experienced pairs } \\
\text { (A and } \mathrm{B} \text { ), single pass }\end{array}$ & $\begin{array}{l}\text { A: } 2.95 \\
\text { B: } 2.58\end{array}$ & $\begin{array}{l}\text { A: } 2.40-3.62 \\
\text { B: } 2.30-2.89\end{array}$ \\
\hline $\begin{array}{l}\text { Line transect: experienced pairs } \\
\text { (A and B), double pass }\end{array}$ & $\begin{array}{l}\text { A: } 3.08 \\
\text { B: } 2.82\end{array}$ & $\begin{array}{l}\text { A: } 2.52-3.76 \\
\text { B: } 2.48-3.21\end{array}$ \\
\hline $\begin{array}{l}\text { Line transect: combined sample, } \\
\text { double pass }\end{array}$ & 4.04 & $3.16-5.17$ \\
\hline $\begin{array}{l}\text { Plots (complete sample), } \\
\text { uncorrected }\end{array}$ & 4.30 & $2.80-5.80$ \\
\hline $\begin{array}{l}\text { Plots (complete sample), } \\
\text { corrected for missed nests }\end{array}$ & 4.79 & - \\
\hline Female home range estimation & $4.25-4.5$ & - \\
\hline
\end{tabular}

and $23.7 \%$, respectively, compared to the mean increase observed here of $15 \%$ (and 12 and $13 \%$ for the two experienced teams). Nonetheless, it is unlikely that multiple passes produced a 'true' density in their studies. Both Buij et al. (2003) and the present study used independent data to estimate the true density, and found that double-pass line transect estimates, were still far below the estimated true densities. Increasing the number of passes is unlikely to improve this situation: Johnson et al. (2002) did a third pass in some cases, but found very few new nests.

Densities estimated through the line transect method were considerably lower than those obtained by plot counts (Table 2), although the combined line transect sample yielded only marginally lower estimates than those based on plots or female home ranges. Plot counts still missed a small proportion of nests, but came very close to the estimated true density. Thus, the plot method is superior to the line transect method in this case. First, even the best line transect estimates remained well below the true density, by a margin that normally cannot be estimated without resorting to other methods (cf. Fig. 1b). Second, the plot method does not take much more time to produce these better estimates. A double pass of the two line transects would take a pair of observers 2 days (progress is slow and the high number of measurements in the dense forest takes much time). In the same amount of time, this team can cover 10-12 plots. Although estimates based on the combined line transect sample are also reasonably accurate, this procedure requires the presence of multiple teams and tedious and time-consuming data sorting.

The plot method also has a weak point, namely its lower reliability. A relatively larger number of plots is required to reach similar confidence limits to those reached by line transect methods (assuming homogeneous habitats). However, it is obviously better to have an unbiased estimate that can be made reliable with some additional effort (the plot method) than a method that is more reliable but produces an unknown downward bias (line transects). By adding more well spaced plots, one can reduce the confidence limits to the lowest values admitted by habitat heterogeneity. Stratified random sampling of clearly identified habitat types is also easy, because plots can still be classified well after sampling.

In areas where plots can be laid out and traversed with relative ease (as in this peat swamp forest), the results of plot counts should be superior to those of line transects. Indeed, a replication by Simon Husson (unpublished) in another Bornean peat swamp confirmed our conclusion. However, it is not necessarily true that plot counts are equally superior in structurally more complex forests (most dry-land forests). Even though trees can be examined form all angles and all distances, more nests may be missed in plots in such forests. Hence, more comparisons are needed before we can recommend the plot method as universally superior to line transect counts. Nonetheless, we expect that plots 
are more likely to overcome the inherent underestimation of densities due to the nests missed above or near the transect line, assuming that observers are experienced.

The size and shape of plots should depend on forest structure. Plots can be sited around trail intersections to facilitate access and measurement. Great care should not only be taken to identify all the nests in the plots, but also to measure their location and exclude those outside the plot, especially in narrow plots with a relatively long edge. Obviously, using plots does not obviate the need to estimate $t$, but these estimates can be obtained through repeat visits to plots, and are becoming increasingly available for different habitats.

The experiment reported here implies that orangutan densities in the literature are often too low. Most are based on line transects walked by small teams, often involving a double pass. In this study, such estimates (including only experienced teams) were $28-37 \%$ below the best estimate of the true density based on the home range methods, and $28-34 \%$ below the density based on nest counts in plots. Nonetheless, even if actual numbers are significantly higher than many reported to date, the trends in numbers noted by all studies that compared different points in time remain unambiguous. Orangutan habitats are declining seriously in both quality and extent through forest conversion, logging, fires, and poaching; and orangutan numbers almost certainly show the same trend (e.g. Rijksen and Meijaard 1999; van Schaik et al. 2001; Wich et al. 2003).

Acknowledgements We thank the BOS-Foundation for permission to work at Mawas, and its staff for the great support of all activities; the staff and students from Universitas Nasional, Jakarta (Tatang Mitra Setia, Imran Said L. Tobing, Didik Prasetyo, Dwi Mulyawati, Tirza Yohana, Lili Aries Sadikin, Adi Hadinata, Ari Meididit, Fikty Apirlinayati, Fitriah Basalamah, and Ika Mian Karlina) for participating in the line transect experiment; the Indonesian Institute of Sciences (LIPI) for permission to work in Indonesia; the L.S.B. Leakey Foundation for financial support of the Tuanan Orangutan Project; the Netherlands Organisation for Scientific Research for financially supporting S.A. Wich, and Meredith Bastian and Maria van Noordwijk for comments on the MS.

\section{References}

Ancrenaz M, Gimenez O, Ambu L, Ancrenaz K, Andau P, Goossens B, Payne J, Sawang A, Tuuga A, Lackman-Ancrenaz I (2005) Aerial surveys give new estimates for orangutans in Sabah, Malaysia. PLoSBiology 3(1,e3):1-8
Buckland ST, Anderson DR, Burnham KP, Laake JL (1993) Distance sampling: estimating abundance of biological populations. Chapman and Hall, London

Buij R, Wich SA, Lubis AH, Sterck EHM (2002) Seasonal movements in the Sumatran orangutan (Pongo pygmaeus abelii) and consequences for conservation. Biol Cons 107:83-87

Buij R, Singleton I, Krakauer E, van Schaik CP (2003) Rapid assessment of orangutan density. Biol Cons 114:103-113

Cowlishaw G, Dunbar R (2000) Primate conservation biology. University of Chicago Press, Chicago

Ghiglieri MP (1984) The chimpanzees of Kibale forest. Columbia University Press, N.Y.

Hashimoto C (1995) Population census of the chimpanzees in the Kalinzu forest, Uganda: comparison between methods with nest counts. Primates 36:477-488

Johnson AE, Knott CD, Pamungkas B, Pasaribu M, Marshall AJ (2005) A survey of the orangutan (Pongo pygmaeus pygmaeus) population in and around Gunung Palung National Park, West Kalimantan, Indonesia based on nest counts. Biol Cons (in press)

Morrogh-Bernard H, Husson S, Page SE, Rieley JO (2003) Population status of the Bornean orang-utan (Pongo pygmaeus) in the Sebangau peat swamp forest, Central Kalimantan, Indonesia. Biol Cons 110:141-152

Rijksen HR, Meijaard E (1999) Our vanishing relative: The status of wild orang-utans at the close of the twentieth century. Kluwer, Boston

Russon AE, Erman A, Dennis R (2001) The population and distribution of orang-utans (Pongo pygmaeus pygmaeus) in and around the Danau Sentarum Wildlife Reserve, West Kalimantan, Indonesia. Biol Cons 97:21-28

van Schaik CP, Azwar, Priatna D (1995) Population estimates and habitat preferences of orangutans based on line transects of nests. In: Nadler RD, Galdikas BMF, Sheeran LK, Rosen N (eds) The neglected ape. Plenum Press, N.Y., pp129-147

van Schaik CP, Monk KA, Robertson JMY (2001) Dramatic decline in orang-utan numbers in the Leuser ecosystem, Northern Sumatra. Oryx 35:14-25

Singleton IS (2000) Ranging behaviour and seaasonal movements of sumatran orangutans (Pongo pygmaeus abelii) in Swamp Forests. PhD dissertation, University of Kent

Singleton IS, van Schaik CP (2002) The social organization of a population of Sumatran orangutans. Folia Primatol 73:1-20

Thomas L, Laake JL, Strindberg S, Marques FFC, Borchers DL, Buckland ST, Anderson DR, Burnham KP, Hedley SL, Pollard JH (2001) Distance 4.0. Beta 3. Research unit for wildlife population assessment. University of St. Andrews, UK

Wich SA, Singleton I, Utami-Atmoko SS, Geurts ML, Rijksen HD, van Schaik CP (2003) The status of the sumatran orangutan Pongo abelii: an update. Oryx 37:49-54 